\title{
Structure of NG-061, a Novel Potentiator of Nerve Growth Factor (NGF) Isolated from Penicillium minioluteum F-4627
}

\author{
Renuka Bhandari, Tadashi Eguchi, ${ }^{\dagger}$ Akiko Sekine, ${ }^{\dagger}$ \\ Yuji OHASHI ${ }^{\dagger}$ and Katsumi KaKinuma* \\ Department of Chemistry, and Department of Chemistry and Materials Science ${ }^{\dagger}$, Tokyo Institute of Technology, \\ O-okayama, Meguro-ku, Tokyo 152-8551, Japan \\ Mayumi Ito and Kazutoshi Mizove \\ Research Laboratories, Taisho Pharmaceutical Co., Ltd., \\ 1-403, Yoshino-cho, Omiya-shi, Saitama 330-8530, Japan
}

(Received for publication December 15, 1998)

\begin{abstract}
The structure of NG-061, a new potentiator of nerve growth factor (NGF) isolated from Penicillium minioluteum F-4627, was determined by spectroscopic analysis and X-ray diffraction method to be phenylacetic acid 2-(2-methoxy-4-oxocyclohexa-2,4-dienylidene)hydrazide.
\end{abstract}

During the course of our screening program for low molecular weight natural products being able to potentiate and/or mimic neurotrophic effect of NGF, a novel fungal metabolite designated as NG-061, was isolated from the fermentation broth of Penicillium minioluteum F-4627 ${ }^{1)}$. In this paper, we wish to report the structure elucidation of NG-061 (1) by spectroscopic analysis and X-ray diffraction method.

\section{Results and Discussion}

The physico-chemical properties of $\mathbf{1}$ are summarized in Table 1. 1 was isolated as pale yellow crystals, and was found to have molecular formula as $\mathrm{C}_{15} \mathrm{H}_{14} \mathrm{~N}_{2} \mathrm{O}_{3}$ based on the molecular ion peak observed at $m / z 270$ in EIMS and HR-EIMS. The prominent base peak of $\mathrm{m} / \mathrm{z}$ 91 indicated the presence of a mono-alkyl substituted benzene ring in 1 . The UV spectrum of 1 was observed with two maxima at 207 and $340 \mathrm{~nm}$ in methanol. The IR spectrum of 1 showed a strong peak at $3438 \sim 3100$ $\mathrm{cm}^{-1}$ due to a $\mathrm{OH}$ and/or $\mathrm{NH}$ group and two strong absorptions at 1680 and $1640 \mathrm{~cm}^{-1}$, suggesting the existence of a conjugated ketone carbonyl and an amide moiety, respectively.
The ${ }^{1} \mathrm{H}$ and ${ }^{13} \mathrm{C}$ NMR spectra of 1 indicated that 1 existed in two forms in solution probably due to conformational change or tautomerization, and the ratio of two forms varied depending on the solvent; 1) ca. $4: 1$ in $\left.\mathrm{CDCl}_{3}, 2\right) 8: 1 \sim 10: 1$ in dimethyl sulfoxide- $d_{6}$, and 3) $1: 1$ in pyridine- $d_{5}$. The ${ }^{1} \mathrm{H}$ and ${ }^{13} \mathrm{C}$ NMR data in $\mathrm{CDCl}_{3}$ solution were summarized in Table 2 . The ${ }^{1} \mathrm{H}$ NMR spectrum showed 14 hydrogens, which is consistent with its molecular formula. The signal at $\delta_{\mathbf{H}} 3.89$ for $3 \mathrm{H}$ and the broad signal for $2 \mathrm{H}$ at $\delta_{\mathrm{H}} 4.12$ were straightforwardly assigned to a methoxy group and a methylene group, respectively, from ${ }^{1} \mathrm{H}$ and ${ }^{13} \mathrm{C}$ NMR data, and HMQC spectrum. The singlet at $\delta_{\mathrm{H}} 5.86$ was assigned to

Fig. 1. Structure of NG-061.

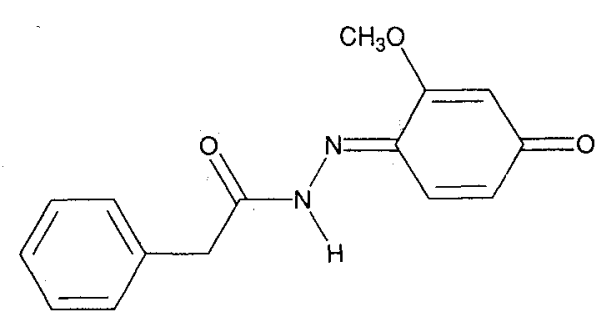


Table 1. Physico-chemical properties of NG-061.

\begin{tabular}{ll}
\hline Appearance & Pale yellow crystal \\
Melting point & $189-190^{\circ} \mathrm{C}$ \\
EI-MS $m / z$ (rel. intensity, \%) & $270\left(95, \mathrm{M}^{+}\right), 179(8), 153(17), 152(15)$, \\
& $125(29), 91(100)$ \\
HR-EIMS $(m / z)$ & \\
Found & 270.1002 \\
Calcd. for $\mathrm{C}_{15} \mathrm{H}_{14} \mathrm{~N}_{2} \mathrm{O}_{3}$ & 270.1004 \\
Molecular formula & $\mathrm{C}_{15} \mathrm{H}_{14} \mathrm{~N}_{2} \mathrm{O}_{3}$ \\
$\mathrm{UV} \lambda_{\max } \mathrm{nm}(\varepsilon)$ in methanol & $207(15,100), 340(30,300)$ \\
IR $v_{\max } \mathrm{cm}^{-1}(\mathrm{KBr})$ & $3438,3111,1680,1640,1569,1543$ \\
\hline
\end{tabular}

Table 2. ${ }^{13} \mathrm{C}$ and ${ }^{1} \mathrm{H}$ NMR data of NG-061

\begin{tabular}{ccl}
\hline Carbon No. & $\delta_{\mathrm{C}}$ & $\delta_{\mathrm{H}}$ \\
\hline 1 & 38.7 & $4.12(2 \mathrm{H}, \mathrm{broad} \mathrm{s})$ \\
2 & 56.2 & $3.89(3 \mathrm{H}, \mathrm{s})$ \\
3 & 106.9 & $5.86(1 \mathrm{H}, \mathrm{s})$ \\
4 & 127.1 & $7.28(1 \mathrm{H}, \mathrm{m})$ \\
5 & 128.5 & $6.34(1 \mathrm{H}, \mathrm{d}, J=10.0 \mathrm{~Hz})$ \\
6 & $128.6(2 \mathrm{C})$ & $7.3(2 \mathrm{H}, \mathrm{m})$ \\
7 & $129.4(2 \mathrm{C})$ & $7.3(2 \mathrm{H}, \mathrm{m})$ \\
8 & 132.8 & \\
9 & 133.8 & $7.07(1 \mathrm{H}, \mathrm{d}, J=10.0 \mathrm{~Hz})$ \\
10 & 138.6 & \\
11 & 159.9 & $11.34(1 \mathrm{H}, \mathrm{N}-\mathrm{H})$ \\
12 & 174.0 & \\
13 & 186.5 & \\
\hline
\end{tabular}

a The data were reported for the major peaks of $\mathrm{NG}-061$ in $\mathrm{CDCl}_{3}$.

an olefinic proton, which showed a cross peak with the carbon at $\delta_{\mathrm{C}} 106.9$ in the HMQC spectrum. The doublet at $\delta_{\mathbf{H}} 6.34$ was also due to an olefinic proton, which in turn coupled with the proton at $\delta_{\mathrm{H}} 7.07$ by $J=10 \mathrm{~Hz}$. The multiplet $(5 \mathrm{H})$ observed at $\delta_{\mathrm{H}} 7.28 \sim 7.30$ were correlated to carbon signals at $\delta_{\mathrm{C}} 127.1,128.6$, and 129.4 in the HMQC spectrum, indicating the presence of a monosubstituted benzene ring. An exchangeable broad signal was observed at $\delta_{\mathbf{H}} 12.40$, which can be assigned to an amide proton.

The HMBC experiments confirmed the heteronuclear. connectivities in $\mathbf{1}$ which are shown in Figure 2. The correlations of the methylene protons at $\delta_{\mathrm{H}} 3.89$ with a carbonyl carbon at $\delta_{\mathrm{C}} 174.0$ and the phenyl carbon indicated the presence of a phenylacetyl group. Other correlations from the olefinic protons at $\delta_{\mathrm{H}} 5.86,6.34$, 
and 7.07 suggested that the structure of $\mathbf{1}$ is composed of cyclohexadienone moiety.

The remained structure of $\mathbf{1}$ was the linkage between the phenylacetyl group and cyclohexadienone group. Since additional information was not available from the NMR spectra, the X-ray crystallographic analysis was persued. Fortunately, 1 formed suitable needle crystals for X-ray analysis by recrystallization from $\mathrm{CH}_{3} \mathrm{CN}$. As shown in Figure 3, the ORTEP drawing clearly showed an acyl hydrazone structure in 1, and finally, the structure of 1 was unambiguously determined to be phenylacetic acid 2-(2-methoxy-4-oxocyclohexa-2,4dienylidene)hydrazide. It is conceivable from this structure that two forms of $\mathbf{1}$ in solution may exist due to

Fig. 2. HMBC connectivities of NG-061.

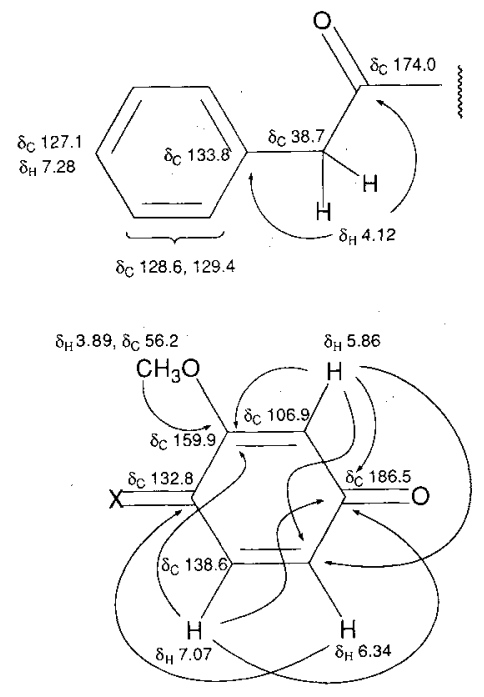

the $S$-cis to $S$-trans isomerization of the amide group or tautomerization in the hydrazide moiety.

It is the first report to our knowledge that a phenylacetic acid (4-oxo-iminoquinone)hydrazide derivative such as $\mathbf{1}$ has been isolated from natural source as a bioactive product. There are only a few reports on phenyl acetic acid hydrazide derivatives. 1,4-Naphtoquinones4-aryl(aroyl)hydrazones were synthesized as possible antituberculous agents ${ }^{2}$ from a lead compound of 3-hydroxy-2-methyl-1,4-napthoquinone with antituberculous activity isolated from acetone extract of Tubercle bacilli. On the development of the method for spectrophotometric determination of hydrazides was detected phenylacetic acid 2-(2,3-dichloro-4-oxo-4H-naphthalene-1-ylidene)hydrazide as a reaction product ${ }^{3)}$. To confirm whether $\mathbf{1}$ is a microbial metabolite or an artifact, we examined the time course of fermentation by extracting the culture broth, and by analyzing the extract with HPLC. The production of $\mathbf{1}$ gradually increased along with the progress of fermentation and reached to a plateau after 48 hours (data not shown). Therefore, it appears that $\mathbf{1}$ was produced as a metabolite produced by Penicillium minioluteum F-4627.

\section{Experimental}

General

Melting point was determined with a Yazawa micromelting point apparatus BY-1. IR spectrum was recorded on a Horiba FT-710 Fourier-transform Infrared spectrometer. UV spectrum was obtained with a Shimadzu UV-160A UV-Visible recording spectrophotometer. Mass spectra was determined with a JEOL

Fig. 3. ORTEP ${ }^{8)}$ drawing of NG-061 showing the atomic labelling.

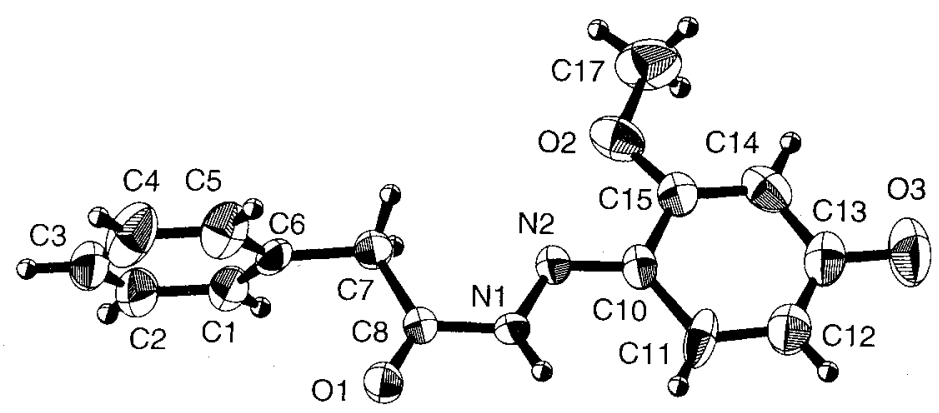

$50 \%$ Probability thermal ellipsoids for non-hydrogen atoms are shown. $\mathrm{H}$ atoms are shown as small spheres of arbitrary radii. 
JMS-AX505 HA Mass spectrometer. NMR spectra were measured on a Bruker DRX 500 spectrometer.

\section{X-ray Crystalography}

Crystal data: Monoclinic, $a=26.5053(12), b=6.5972$ (3), $c=17.2633(4) \AA, b=117.261(4)^{\circ}, V=2683.4(2) \AA^{3}$, $\mathrm{Z}=8$, space group $\mathrm{C} 2 / \mathrm{c}, \mathrm{Dc}=1.338 \mathrm{Mg} \mathrm{m}^{-3}, \mu=0.087$ $\mathrm{mm}^{-1}$. Data collection: The X-ray analysis was carried out by Siemens Smart CCD diffractometer ${ }^{5)}$ with graphite monochromated Mo- $K \alpha$ radiation $(\lambda=0.71073 \AA)$ using pale yellow needle crystal, $0.28 \times 0.09 \times 0.07 \mathrm{~mm}$ at $-50^{\circ} \mathrm{C}$ with low temperature apparatus. A total of 6354 reflections measured, of which 1936 are unique. Data were corrected for Lorentz and polarization effects. Semi-empirical absorption correction ${ }^{6)}$ was applied. Structure analysis and refinement: The crystal structure was solved by the direct methods with the program SIR- $92^{7}$, and refined by full-matrix least-squares on $\mathrm{F}^{2}$ values using SHELXL-97 ${ }^{8}$. Non-hydrogen atoms were refined with anisotropic temperature factors. Hydrogen atoms were included at calculated positions and refined in the riding mode except one bonding to the $\mathrm{N}$ atom, which was refined without constraint. The final $\mathrm{R}$ and $w \mathrm{R} 2$ for 1163 reflections with $\mathrm{I}>2 \sigma(\mathrm{I})$ were 0.10 and 0.28 , respectively and $S=1.05$. In the final refinement $(\Delta / \sigma)$ max became 0.001 . Although there were two significant residual peaks, $0.8 \sim 0.9 \mathrm{e} \AA^{-3}$, they were at meaningless positions even if the disordered model was taken into account.

\section{References}

1) Ito, M.; N. Sakai, K. Ito, F. Mizobe, K. Hanada, K. Mizoue, R. Bhadari, T. Eguchi \& K. Kakinuma: A novel fungal metabolite NG-061 enhances and mimics neurotrophic effect of nerve growth factor (NGF) on neurite outgrowth in PC12 Cells. J. Antibiotics 52: 224 230, 1999

2) Roushdi, I. M.; E. S. Ibrahim \& N. S. Habib: Synthesis of 1,4-naphthoquinone-4-aryl(aroyl)hydrazones of potential antimicrobial activity. Pharmazie 31: $856 \sim 859$, 1976

3) Plaizier, J. A.; J. G. van Damme \& R. E. De Neve: Spectrophotometric determination of hydazides with 2,3-dichloro-1,4-naphtoquinone. Anal. Chem. 48: $1536 \sim 1538,1976$

4) JOHNSON, C. K.: ORTEP II. Report ORNL-5138. Oak Ridge National Laboratory, Tennessee, USA, 1976

5) Siemens: SMART. Area Detector Control Software. Siemens Analytical X-ray Instruments Inc., Madison, Wisconsin, USA, 1996

6) SHeldrick, G. M.: SADABS. Siemens Area Detector Absorption Correction Software. University of Göttingen, Germany, 1996

7) Altomare, A.; G. Cascarano, C. Giacovazzo, A. Guagliardi, M. C. Burla, G. Polidori \& M. CAMALLI: SIR92 - a program for automatic solution of crystal structures by direct methods. J. Appl. Cryst. 276: $435 \sim 457,1994$

8) SHELDRICK, G. M.: SHELXL-97 Program fot the Refinement of Crystal Structures, University of Göttingen, Germany, 1997 